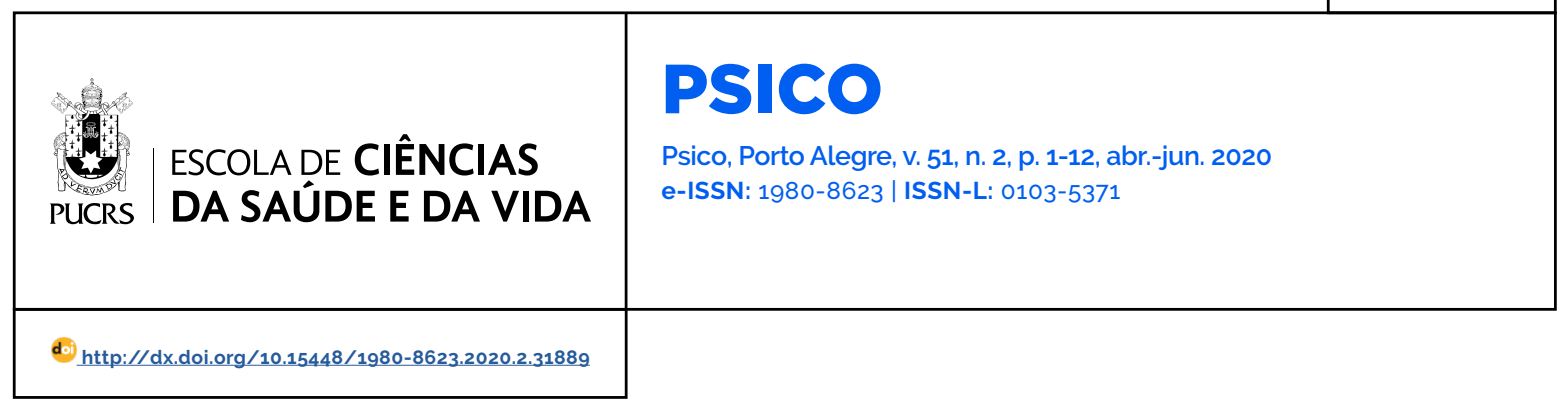

SEÇÃO: ARTIGO

\title{
Retrospectiva da experiência de gestação de mulheres com depressão pós-parto: estudo comparativo
}

\author{
Retrospective gestational experience of women with postpartum depression: a \\ comparative study \\ Retrospectiva de la experiencia de gestación para mujeres con depresión posparto: \\ estudio comparativo
}

\section{Monique Souza \\ Schwochow ${ }^{1}$ \\ orcid.org/0000-0002-4424-5005 \\ moniqueschwochow@gmail.com}

Giana Bitencourt Frizzo ${ }^{1}$

orcid.org/0000-0001-8106-4441 gifrizzo@gmail.com

Recebido em: 10 set. 2018 Aprovado em: 4 dez. 2019 Publicado em: 4 set. 2020

\begin{abstract}
Resumo: A sobrecarga emocional própria das vivências do tornar-se mãe pode, frequentemente, levar ao desenvolvimento da depressão pós-parto. Diante disto, este estudo buscou compreender, de forma retrospectiva, a experiência de gestação de mães com e sem depressão pós-parto. As participantes foram seis mães, com idades entre 28 e 38 anos. Três mães não apresentaram quaisquer transtornos de humor e três tiveram o diagnóstico de depressão pós-parto confirmado. A base para a análise qualitativa desse estudo foi uma entrevista sobre a gestação e o parto. Os resultados indicaram que a experiência de maternidade tem relação estreita com a forma como as mães lidaram com a necessidade de adaptação frente à maternidade, bem como com o desejo e o planejamento - ou não - da gestação. Os achados apoiam a sugestão da literatura que indica a presença de relatos negativos sobre a experiência de maternidade por mães deprimidas, inclusive sobre a gestação.

Palavras-chave: gestação, maternidade, depressão pós-parto.
\end{abstract}

\begin{abstract}
Postpartum depression is a frequent disorder considering the overwhelming emotional experience of becoming a mother. This study sought to understand, retrospectively, the experience of pregnancy of mothers with and without postpartum depression. The participants was six mothers, aged between 28 and 38 years. Three of them did not show any mood disorders and the three others were diagnosed with postpartum depression. The basis for the qualitative analysis of this study was an interview about pregnancy and childbirth. The findings indicated that maternal experience is related to how mothers dealt with the need for adaptation following motherhood, as well as the desire and planning - or not - of pregnancy. The results support the literature that indicates the presence of negative reports about motherhood experience by depressed mothers, including pregnancy period. Keywords: pregnancy, motherhood, postpartum depression.
\end{abstract}

Resumen: La sobrecarga emocional presente en las vivencias del proceso de convertirse en madre puede conducir al desarrollo de la depresión posparto. Por lo tanto, esta investigación trata de comprender de forma retrospectiva la experiencia de gestación de madres con y sin depresión posparto. Participaran seis madres, entre 28 y 38 años de edad. Tres no mostraron ningún trastorno del humor y tres fueron confirmados con depresión post-parto. Sirvió de base para el análisis cualitativo desta investigación una entrevista sobre la gestación y el parto. Los resultados indicaran que la experiencia de la maternidad está estrechamente relacionado con cómo las madres se ocupan de la necesidad de adaptar adelante a la maternidad, asi como el deseo y la planificación - o no - del embarazo. Los resultados apoyan la literatura que indica la presencia de informes negativos sobre la experiencia de la maternidad en madres deprimidas, inclusive durante el embarazo.

Palabras clave: embarazo, maternidad, depresión posparto. 
A chegada de um bebê é considerada um dos eventos mais desafiadores da vida de uma mulher (Henriques, Santos, Caceiro, \& Ramalho, 2015) e, talvez por essa razão, as exigências de adaptação desse acontecimento podem ser consideradas fatores de risco para a depressão no periodo pósparto (Piccinini, Carvalho, Ourique, \& Lopes, 2012). É preciso estar consciente que os dias seguintes ao nascimento são marcados pelo início de um longo processo de reconhecimento, uma vez que o período pós-parto exige da mãe que ela aprenda a lidar com as frustrações de um bebê que não representa a perfeição idealizada e que também causará momentos de sofrimento (Maldonado, 2002).

De acordo com a American Psychological Association (2013), a depressão pós-parto enquadra-se como um especificador do transtorno depressivo maior, compreendendo o momento gestacional e as quatro semanas iniciais após o parto. No entanto, diversas pesquisas têm sugerido, cada vez mais, o estudo da depressão pós-parto até um ano após o nascimento do bebê (Frizzo, Prado, Linares, \& Piccinini, 2010; Haran, Van Driel, Mitchell, \& Brodribb, 2014; Wisner et al., 2013). Ainda, alguns estudos mostram que a depressão pós-parto é considerada a complicação psiquiátrica mais comum entre as mulheres que dão à luz (Brockington, Butterworth, \& GlangeaudFreudenthal, 2016; Gazal et al., 2012), variando entre $10 \%$ e $20 \%$ dos casos - dependendo da ocasião e do método utilizado para o diagnóstico, além da cultura das mães analisadas (Cantilino, Zambaldi, Sougey, \& Rennó, 2010).

A relação entre os sintomas depressivos e o tornar-se mãe remete a algumas inferências. Sousa, Prado e Piccinini (2011) afirmam que a depressão pode refletir em transformações do processo de construção da maternidade para a mulher. Ainda, ela pode repercutir na dinâmica familiar, bem como na qualidade de vida e na interação mãe-bebê, visto que as crianças são vulneráveis ao impacto do humor deprimido de suas mães (Campos \& Rodrigues, 2015). Os prejuizos no aspecto emocional dessas mães e/ou na relação delas com seus filhos podem ocorrer também após o puerpério, nos anos subsequentes do desenvolvimento dessa relação, mostrando, assim, a importância do cuidado da saúde mental da mãe e de seu bebê no período pós-parto (Maldonado, 2002; Milgrom \& Gemmill, 2014).

O estudo de Sousa et al. (2011) evidenciou a existência de representações negativas a respeito da maternidade em mães deprimidas. Foram apontados aspectos como o sentimento de pouco apoio por parte do companheiro nos cuidados com o bebê, além da dificuldade de compreender as necessidades de seu bebê, bem como o sentimento de não ser capaz de cuidar dele. A dificuldade na conciliação entre os antigos papéis e o novo papel de mãe também foi encontrada nesse estudo, demonstrando, assim, a grande necessidade de ajustamento da mulher frente à maternidade.

Estudos mais recentes têm voltado seus olhares para o periodo gestacional por compreenderem sua importância na detecção da depressão pósparto. Muitas vezes, as mulheres diagnosticadas com depressão após o parto também estavam deprimidas durante sua gestação (Alvarenga \& Frizzo, 2017; Field, 2017). Episódios depressivos ou ansiosos na gestação, eventos estressantes, conflitos conjugais, pouco suporte financeiro e social (Cantilino et al., 2010; Robertson, Grace, Wallington, \& Stewart, 2004) e a história pessoal de depressão (Aliane, Mamede, \& Furtado, 2011; Megnin-Viggars, Symington, Howard, \& Pilling, 2015) são fatores de risco associados à depressão pós-parto.

Ainda, estudos como o de Eastwood, Jalaludin, Kemp, Phung, \& Barnett (2012) e o de Lancaster et al. (2010) apontaram que mães com depressão durante a gravidez costumam ter percepções negativas sobre sua experiência de gestação e de maternidade. É preciso recordar, contudo, que o não desejo de uma gestação também é fator de risco para a depressão das mães (Abassi, Chuang, Dagher, Zhu, \& Kjerulff, 2013). Além disso, o estudo de Moraes et al. (2006) sugeriu que os fatos de a mãe ter uma preferência pelo sexo do bebê e de ter pensado em interromper a gestação também estão associados à depressão pós-parto. Portanto, a dificuldade em aceitar a gravidez pode ser um fator que aumenta as chances para a depressão pós-parto. 
Como forma de lidar com esse problema que afeta a saúde mental da mãe e de seu bebê. diversos estudos sugeriram o aperfeiçoamento de trabalhos de atenção materna para prevenir e auxiliar no tratamento da depressão pré e pós-parto (Arrais, Mourão, \& Fragalle, 2014; Eastwood et al., 2012; Howard et al., 2014; Sousa et al., 2011). Nesse sentido, o presente estudo buscou compreender, de forma retrospectiva, a experiência de gestação de mães com e sem depressão pós-parto através da comparação de casos.

\section{Método}

\section{Participantes}

Participaram deste estudo seis mães. Na Tabela 1 podem ser verificados os dados sociodemográficos das participantes.

Tabela 1 - Dados sociodemográficos das participantes

\begin{tabular}{|c|c|c|c|c|c|c|c|c|}
\hline Participante & Idade & $\begin{array}{c}\text { Estado } \\
\text { Civil }\end{array}$ & Escolaridade & $\begin{array}{l}\text { Idade do } \\
\text { bebê }\end{array}$ & $\begin{array}{l}\text { Sexo do } \\
\text { bebê }\end{array}$ & $\begin{array}{l}\text { Outros } \\
\text { filhos }\end{array}$ & $\begin{array}{l}\text { Resultado } \\
\text { no EPDS a }\end{array}$ & $\begin{array}{l}\text { Resultado } \\
\text { no MINI b }\end{array}$ \\
\hline Caso $1\left(\mathrm{M}_{1}\right)^{\mathrm{c}}$ & $\begin{array}{c}38 \\
\text { anos }\end{array}$ & Casada & Pós-graduação & $\begin{array}{c}11 \\
\text { meses }\end{array}$ & Masculino & Sim & 12 & $\begin{array}{c}\text { Episódio de } \\
\text { Depressão } \\
\text { Maior Atual }\end{array}$ \\
\hline Caso 2 (M2) & $\begin{array}{c}33 \\
\text { anos }\end{array}$ & Casada & Pós-graduação & $\begin{array}{c}7 \\
\text { meses }\end{array}$ & Feminino & Não & 18 & $\begin{array}{c}\text { Episódio de } \\
\text { Depressão } \\
\text { Maior Atual }\end{array}$ \\
\hline Caso 3 (M3) & $\begin{array}{c}37 \\
\text { anos }\end{array}$ & Casada & $\begin{array}{l}\text { Fundamental } \\
\text { Incompleto }\end{array}$ & $\begin{array}{c}9 \\
\text { meses }\end{array}$ & Masculino & Sim & 19 & $\begin{array}{c}\text { Episódio de } \\
\text { Depressão } \\
\text { Maior Atual }\end{array}$ \\
\hline Caso 4 (M4) & $\begin{array}{c}34 \\
\text { anos }\end{array}$ & Casada & Pós-graduação & $\begin{array}{c}7 \\
\text { meses }\end{array}$ & Feminino & Não & 06 & - \\
\hline Caso 5 (M5) & $\begin{array}{c}28 \\
\text { anos }\end{array}$ & Casada & $\begin{array}{l}\text { Superior Com- } \\
\text { pleto }\end{array}$ & $\begin{array}{c}11 \\
\text { meses }\end{array}$ & Masculino & Sim & 05 & - \\
\hline Caso 6 (M6) & $\begin{array}{c}36 \\
\text { anos }\end{array}$ & Casada & Pós-graduação & $\begin{array}{c}7 \\
\text { meses }\end{array}$ & Feminino & Não & 05 & - \\
\hline
\end{tabular}

Nota. ${ }^{a}$ EPDS: Escala de Depressão Pós-Natal de Edimburgo.

b MINI: Mini International Neuropsychiatric Interview.

cA letra "M" refere-se a participante mãe.

As mães investigadas possuiam idades entre 28 e 38 anos, tiveram seus bebês a termo, e responderam aos instrumentos e a entrevista quando seus bebês tinham entre sete e onze meses de vida. As mães selecionadas faziam parte do projeto intitulado Depressão pós-parto: Prevalência, antecedentes e intervenção (Frizzo, Piccinini, Silva, Levandowski, \& Donelli, , 2012). Para o presente estudo, foram selecionadas, aleatoriamente: três mães com depressão pósparto identificada pela Escala de Depressão PósNatal de Edimburgo (EPDS) e diagnosticada através do instrumento Mini International Neuropsychiatric Interview - PLUS (MINI-PLUS); e outras três mães sem sintomas de depressão pós-parto. Essa amostra corresponde aos primeiros seis casos coletados no projeto de pesquisa mencionado.

As mães participantes tinham idade superior a dezoito anos e nível socioeconômico e configuração familiar diversas. Os critérios de exclusão eram: mães com déficit intelectual grave - observado a partir do contato com a mãe - e outros quadros psicopatológicos severos, tais como esquizofrenia, transtorno de personalidade borderline e antissocial, regressão psicótica, risco de suicídio e abuso de substâncias químicas identificados a partir da aplicação da MINI-PLUS. Ainda, foram excluídas as diades nas quais os 
bebês apresentaram malformações e outros quadros clínicos, a fim de evitar distorção entre sinais e sintomas próprios do diagnóstico e aqueles indicativos de sintomas psicofuncionais.

\section{Instrumentos}

\section{Mini International Neuropsychiatric Interview} (MINI-PLUS). Elaborada por Sheehan et al. (1998) e traduzida por Amorim (2000), trata-se de uma entrevista diagnóstica padronizada breve, com aplicação de cerca de 15-30 minutos, que explora 17 transtornos psiquiátricos do Eixo I do DSMIV (American Psychological Association, 1994), além do risco de suicídio e do Transtorno de Personalidade Antissocial. Também permite identificar participantes com Transtorno de Personalidade Borderline, com regressão psicótica e com ansiedade de separação. São 19 módulos independentes, elaborados de forma a otimizar a sensibilidade do instrumento, a respeito de um possivel aumento de falso-positivos. Cada módulo segue uma organização estabelecida de questionamentos, que levam, em sua maioria, a possibilidade de respostas dicotômicas. Ao final de cada módulo, o entrevistador deve fazer o levantamento das respostas conforme a indicação informada. As orientações para o diagnóstico variam de acordo com o módulo explorado.

Escala de Depressão Pós-natal de Edimburgo (EPDS). Consiste em um instrumento de autoavaliação composto por 10 itens referentes aos sintomas depressivos frequentemente observados no puerpério, validado para o contexto brasileiro (Santos et al., 2007). A EPDS tem respostas objetivas, no formato tipo Likert - ou seja, o sujeito busca a concordância com alguma das afirmações dadas como possiveis respostas. A mãe que responde ao EPDS deve identificar alternativas as quais acredita que descrevem, da melhor forma, como ela tem se sentido na última semana (Camacho et al., 2006). Cruz, Simões e Faisal-Cury (2005) indicam que os itens da Escala podem identificar sintomas como redução de desempenho e culpa, perda de prazer e apetite, distúrbio do sono, humor deprimido ou disfórico e ideação suicida. Criada em 1987, ela foi traduzida e validada para o Brasil somente no ano de 2000, e tem auxiliado no rastreamento de depressão pós-parto, em especial em pesquisas, por todo o pais (Camacho et al., 2006). O escore máximo do EPDS é de 30 pontos, para esse estudo foi utilizado ponto de corte em 10 ou mais pontos, conforme indicado na validação no instrumento (Santos et al., 2007) para identificação da presença de sintomas de depressão.

\section{Entrevista sobre a Gestação e o Parto (NUDIF,} 2003). Trata-se de uma entrevista estruturada, realizada de modo semidirigido, com objetivo de investigar as impressões maternas sobre a gestação e o parto. A entrevista é composta por dois blocos de questões. No primeiro deles investigamse diversos aspectos referentes ao periodo da gravidez, tais como: planejamento e sentimentos da mãe, do pai e dos familiares com a noticia da gestação; estado físico e emocional da mãe e do pai nesse periodo; principais preocupações consigo e com o bebê; mudanças e apoio percebidos. No segundo investiga-se o parto e os primeiros dias após o nascimento do bebê. Entre os aspectos abordados, destacam-se: tipo de parto; ocorrência de complicações; principais preocupações em relação a si mesmo(a) e ao bebê; mudanças percebidas em si mesmo(a) e nos familiares com o nascimento do bebê; e sentimentos a respeito das primeiras horas e dias após o nascimento.

\section{Procedimentos}

O projeto de pesquisa do qual o presente estudo faz parte foi aprovado pelo Comitê de Ética do Instituto de Psicologia da Universidade Federal do Rio Grande do Sul e atende à resolução 466/2012 sobre pesquisa com seres humanos (CAEE 14094213.5.1001.5334).

As mães foram convidadas a participar do estudo através de divulgações da pesquisa em mídias sociais digitais e através de indicações da rede de profissionais conhecidos pelos pesquisadores. Após o contato inicial para participação no estudo, as mães foram convidadas a comparecer ao Instituto de Psicologia da Universidade Federal do Rio Grande do Sul, onde assinaram um Termo de Consentimento 
Livre e Esclarecido (TCLE). Depois desse procedimento, elas preencheram uma Ficha de Dados Sociodemográficos e responderam à MINI-PLUS e à EPDS, em local reservado. Posteriormente, foi realizada a Entrevista Sobre a Gestação e o Parto (Nudif, 2003).

Foi utilizado um delineamento de estudo de casos múltiplo (Yin, 2015), com estratégia geral de análise baseada em uma estrutura descritiva, para derivar uma sintese de casos cruzados. A partir da leitura exaustiva da Entrevista Sobre Gestação e Parto (Nudif, 2003), foi construido o relato descritivo de cada caso, atentando às questões sobre percepção da experiência de gestação, especialmente, no que diz respeito ao planejamento e ao desejo de engravidar e ter filhos. Compreende-se, portanto, que, através de uma abordagem dedutiva, foram unidades de análise desse estudo: a descrição da experiência de gestação, incluindo a reação frente à notícia da gravidez, e o desejo e o planejamento da gestação. Ainda, a partir da leitura da entrevista, surgiu, de forma indutiva, a unidade de análise: apoio (ou não) do companheiro à gestação. Cada caso foi comparado inicialmente ao seu mesmo grupo de casos (com e sem depressão). Após isso, procedeuse a sintese geral dos casos cruzados, a fim de compreender, de forma retrospectiva, a experiência de gestação de mães com e sem depressão pósparto através da comparação de casos.

\section{Resultados}

Para fins de descrição, as mães tiveram seus nomes substituidos pela letra " $M$ ", seguida do número do caso descrito, e os bebês são mencionados através da letra "B", também seguida do número do caso. Ainda, os pais são identificados como "P" e os irmãos como "I", somando-se às letras o número do caso.

\section{Descrição dos Casos}

Caso 1. M1 tinha 38 anos de idade quando foi entrevistada, e seu bebê, B1, tinha 11 meses de vida. Os resultados da EPDS e da MINI-PLUS evidenciaram indicadores de Episódio Atual de Transtorno Depressivo Maior. B1 é o segundo filho do casal M1 e P1 (33 anos) - há 13 anos juntos - e vive com os pais, a irmã (l1), de dois anos e cinco meses, e a avó materna de criação.

A mãe comentou que sempre imaginou ter três filhos. Contou, ainda, que seu esposo desejava ter um segundo filho e que eles pensavam em ter outro bebê quando a primeira filha completasse dois anos de idade. De acordo com seu relato, M1 engravidou de B1 de forma não planejada, quando a filha mais velha estava com oito meses de idade. Segundo ela, a preguiça levou o casal a ter relações sexuais sem uso de preservativo. Lembrou que repetiu o teste de gravidez diversas vezes, pois não acreditava naquela gestação, e disse: "[eu] não contava pra ninguém porque não era o que eu queria." (M1, comunicação pessoal, 23 Fev. 2014). A mãe relatou que demorou cerca de um mês para contar para o esposo sobre a gestação e que isso aconteceu em um momento em que os dois estavam discutindo, e ela revelou: "para de me encher o saco porque eu estou grávida" (M1, comunicação pessoal, 23 Fev. 2014). A reação inicial do marido foi ficar paralisado, mas logo em seguida "deu uma risadinha" (M1, comunicação pessoal, 23 Fev. 2014), segundo a mãe. Ela complementou, ainda, dizendo: "ele queria outro filho, mas queria outro filho até conhecer o B1, como eu digo" (M1, comunicação pessoal, 23 Fev. 2014). Ela diz que seu segundo filho não foi rejeitado, e sim inesperado, mas que as coisas complicaram muito depois que ele nasceu. Ao longo da entrevista, a mãe contou que, durante a gestação, os momentos que costumavam gerar emoção e expectativa nas grávidas, como a ultrassonografia, ela "fazia sem afeto, fazia sem emoção" (M1, comunicação pessoal, 23 Fev. 2014)

Durante toda entrevista, ficou evidente a comparação entre os filhos B1 e l1. A mãe referiuse à gestação da filha mais velha como tranquila e, em seguida, contou que a gestação do filho mais novo foi "[um] caos", uma gravidez muito agitada. Expôs que, durante a gestação, dizia para seu filho: "mamãe te ama, mas não te atura" (M1, comunicação pessoal, 23 Fev. 2014). Quanto ao apoio do companheiro durante a gestação, a mãe queixou-se bastante, dizendo que esse não agiu 
com o carinho e o cuidado que tinha proporcionado a ela na gestação de sua filha mais velha. Pelos relatos da mãe, o casal não estava vivenciando um bom momento e tinham muitos conflitos, especialmente porque seu esposo atribuía muitas tarefas a ela. A mãe comparou o bebê ao marido dizendo que "o B1 chorando no meu ouvido é como se fosse o P1 reclamando (...) a chatice é igual" (M1, comunicação pessoal, 23 Fev. 2014).

Ainda sobre a gestação, contou com pouca afetividade sobre o momento do parto. A mãe lembrou-se que pediu ao filho: "fica mais tempo, fica, fica, fica [na barriga] até quando der, pra eu poder descansar um pouco" (M1, comunicação pessoal, 23 Fev. 2014). B1 nasceu com 38 semanas de gestação. A respeito dos primeiros dias com o filho, ela relatou que "eu tenho certeza que eu estava rejeitando aquela criança" e, ainda, que "eu tentava me esforçar pra ser a mãe que eu gostaria de ser, porque eu fui com a minha filha mais velha, mas eu não sentia vontade. Me dava mais raiva ainda, eu pensava no dia que não usei camisinha". Por fim, a mãe disse: "eu me culpava, mas não sei (...) ao mesmo tempo é uma raiva e uma tristeza" (M1, comunicação pessoal, 23 Fev. 2014) e encerrou contando que não sente "normalidade" no bebê, o que sugere uma suspeita com relação a algum problema no desenvolvimento do filho. No momento da entrevista, a mãe não desejava mais ter três filhos, como havia mencionado, pois disse que depois da experiência com B1, necessitou refletir sobre este plano.

Caso 2. M2 tinha 32 anos e seu bebê, B2, tinha sete meses de idade na ocasião da entrevista. Tanto a MINI-PLUS, quanto a EPDS, mostraram indicadores de depressão pós-parto na época. B2 é a primeira filha do casal. Ela mora com a mãe, M2, e com o pai, P2 (40 anos), que estão juntos há nove anos.

A mãe disse que seu esposo sonhava mais com a parentalidade do que ela e que, logo que ele soube que seria pai, chorou de felicidade. M2 contou que se sentiu feliz ao saber da notícia da gestação, apesar de referir que por muito tempo não pensava em ser mãe, devido ao medo que sentia do processo gestacional. Ela falou que pensava que a gestação seria "um transtorno horrivel", mas que o fato de não ter muitos enjoos, nem grandes mudanças físicas mudou o seu conceito sobre gravidez. O pai foi a todas as consultas com ela e estava presente no parto. M2 descreve o marido como "bem companheirão" e diz que se sentiu "superprotegida e tranquila" em relação ao apoio que recebeu durante a gestação (M2, comunicação pessoal, 12 Ago. 2014).

A gestação foi planejada pelo casal e a mãe relatou que a gravidez aconteceu em um momento bastante tranquilo para ela e seu esposo. No entanto, ao longo da entrevista, contou que, ao mesmo tempo em que estava grávida, o casal reformava seu apartamento e que aquele fora um momento em que se sentiu bastante estressada e limitada pela gestação, visto que o marido dizia para ela não ir no local para não se incomodar com os problemas da obra, ou então com o mau cheiro. M2 disse "eu sou uma pessoa muito de [ação], era antigamente, hoje eu sou um pouco menos por causa da B2", e completou: "alguém me bloqueou, eu, poxa, perdi a minha liberdade'" (M2, comunicação pessoal, 12 Ago. 2014). Quanto ao estresse, a mãe contou que, no momento da obra no apartamento, se questionava o porquê de a gestação acontecer justamente naquele periodo da vida dela. M2 sentiu uma perda de autonomia que a incomodou significativamente.

Caso 3. M3 (37 anos) é mãe de B3, que tinha, no periodo da entrevista, nove meses de vida. Os resultados da EPDS e da MINI-PLUS, aplicadas na ocasião, apontaram indicadores de depressão pós-parto. B3 vive com a mãe, o pai (P3), 31 anos, e o irmão (I3) de nove anos de idade. O casal tem um relacionamento de 13 anos e mora próximo à familia de $\mathrm{M} 3$.

A gestação de B3 não foi planejada e também não era desejada pela mãe, que pensava em ter apenas um filho, pois acreditava que não teria condições psicológicas para dar atenção e cuidar de outra criança. Quando soube o resultado do exame de gravidez, ficou "sem reação, sem ação", enquanto o marido festejava a notícia. Ela contou que descobriu que estava grávida na véspera do ano novo e que, naquele momento, estava 
fazendo muitos planos para o ano que viria, mas que a notícia da gestação a deixara bastante confusa. Ela relatou: "eu estava planejando sair, viajar, dai quando eu descobri que estava grávida, já foi, eu parei no mundo, né". E completou: "eu, dentro de mim, eu... pra eu aceitar assim, foi bem dificil (...)" (M3, comunicação pessoal, 11 Jan. 2014). Segundo M3, seu marido the dera o suporte necessário durante a gestação e o filho mais velho desejava um irmão. Ela contou que, em seu entendimento, a aceitação só veio depois do nascimento e que, em momento algum da gestação, pôde dizer que ficou contente pelo que estava vivendo.

A mãe relatou, ainda, o alerta de uma médica que a acompanhara em seu pré-natal, a qual afirmava que ela estava demonstrando sinais de depressão por não aceitar a gestação e que deveria ter cuidado para não vivenciar uma situação de depressão pós-parto. Na entrevista, não é descrita nenhuma ação de fato em relação aos sintomas, apenas o alerta realizado pela médica. M3 expôs que se sentia muito nervosa durante a gestação, tinha preocupações em relação a "mais um filho no mundo" e à dificuldade de educar uma criança. Ela sentia que não poderia contar com o apoio da família. Disse, ainda, que não organizou o enxoval com o mesmo cuidado que teve na gestação de seu filho mais velho e que deixava tudo sempre para a última hora. $A$ gestação de $\mathrm{M} 3$ foi de risco e exigiu muito repouso, visto que ela tinha frequentes contrações. Já no final da gestação, M3 teve diabetes gestacional e hipertensão, precisando ser internada.

Caso 4. M4 tinha 34 anos de idade quando foi entrevistada e, sua filha, B4, tinha sete meses de vida. Tanto a EPDS, quanto a MINI-PLUS, respondidas no momento da entrevista, excluíram a existência de depressão pós-parto. B4 vivia, na época da entrevista, com os pais, M4 e P4 (33 anos), que estavam juntos há 13 anos.

A gestação de B4 foi planejada e, ainda, a mãe afirmou: "sim, foi desejada, muito!" (M4, comunicação pessoal, 13 Set. 2013). M4 buscou orientação médica para engravidar e durante um ano teve muitos momentos de ansiedade por não entender por qual motivo não conseguia ficar grávida. Com o passar de um ano, ela e seu esposo fizeram exames e descobriram que precisariam recorrer à inseminação artificial para conseguir a desejada gestação. Ela engravidou com esse tratamento e, mesmo com o resultado positivo para gestação, a mãe teve dificuldades para acreditar na notícia. Foram dois anos de espera e, somente depois dos três meses de gestação, a mãe permitiu que a familia comunicasse publicamente sua gravidez, pois tinha receios. Ela pediu: "espera pra ver se vai ficar tudo bem, já foi tão difícil conseguir engravidar!" (M4, comunicação pessoal, 13 Set. 2013). M4 referiu que a notícia da gravidez foi um pouco diferente, pois não foi uma "gestação natural", mas que também sentia bastante expectativa. O pai ficou "super feliz" e a mãe disse que ele acreditava mais do que ela na notícia. M4 descreveu o esposo como "paizão", pois afirmava que ele dera todo suporte necessário durante a gestação e nos primeiros meses de vida da filha. Segundo ela, $\mathrm{P} 4$ realmente se envolveu com a gestação.

Caso 5. M5 tinha 28 anos de idade quando foi entrevistada e seu bebê, B5, tinha nove meses de vida. Os instrumentos MINI-PLUS e EPDS não indicaram a presença de depressão pós-parto na ocasião. B5 vivia, na época da entrevista, com os pais, M5 e P5 (30 anos), e o irmão mais velho, I5 (três anos). O casal vivia junto há oito anos.

B5 foi um bebê planejado e desejado. A mãe tinha o desejo de dar um irmão ao filho mais velho, pois acreditava que ele era muito sozinho e que isso o fazia mal. Ela disse: "(...) um irmão era o melhor presente que a gente podia dar até hoje ele chama de meu presentinho" (M5. comunicação pessoal, 23 Out. 2013). Relatou que, quando engravidou de B5, já fazia cerca de um ano que ela estava tentando ter um bebê. A notícia da gestação deixou todos muito contentes e, apesar das dificuldades da gestação, que exigira cuidados e repouso, a experiência foi vista como tranquila. $A$ mãe atribui as complicações que teve à ansiedade que sentia. Quanto ao apoio do esposo, M5 referiu que P5 sempre a apoiara, e disse: 
Ele é imprescindivel, eu devo muito a ele, a maneira dele de encarar a vida, ele é muito calmo, ele é deficiente físico, ele vê tudo pela ótica boa, não é um deficiente físico que acha tudo ruim, bem pelo contrário, nunca reclama da condição dele, e ele vê tudo pelo lado bom, então isso me faz muito ver que eu to reclamando de barriga cheia, que eu não tenho que reclamar. (M5, comunicação pessoal, 23 Out. 2013)

Ela contou, também, que não esperava muito suporte de sua mãe, e que seus pais não eram presentes na vida de B5.

Caso 6. M6 é mãe de B6, que tinha sete meses de idade na época da entrevista. A mãe tinha 36 anos e o pai, P6, tinha 40 anos. O casal estava junto há oito anos. Não existiam indicadores de depressão pós-parto de acordo com a MINI-PLUS e a EPDS aplicados na ocasião.

A mãe teve um aborto espontâneo cerca de dois anos antes da gestação de B6. Ela descreveu essa vivência como bastante traumática e contou que só conseguira elaborar a perda de seu bebê e começar a pensar em uma nova gestação depois que iniciou uma psicoterapia. Após o tratamento, a gestação foi planejada e era considerada desejada. Apesar de se sentir mais segura sobre a decisão de ser mãe, a nova gestação trouxe muita insegurança e receios em relação à perda do bebê. O casal ficou apreensivo pela situação que tinha passado, mas recebera a notícia da gestação com muita alegria. Quando descobriram a gravidez, decidiram ter cuidado com a divulgação da notícia, pois tinham muito medo de perder o bebê. M6 contou que, somente depois das 24 semanas de gestação, se sentiu mais confiante sobre a gravidez, pois tinha a informação "24 semanas já é um bebê viável" (M6, comunicação pessoal, 20 Jun. 2014). A notícia foi divulgada para a família no aniversário da mãe de M6 e todos ficaram muito felizes.

A mãe relatou que acreditava que ela e o esposo tinham um bom relacionamento e que a relação melhorara depois da gravidez. Disse que P6 sempre a apoiara e dera o suporte necessário, destacando: "foi super parceiro, fez curso de gestantes comigo (...)" (M6, comunicação pessoal, 20 Jun. 2014). Segundo M6, seu marido lia informações sobre amamentação e maternidade e partilhava com ela suas reflexões. Durante a entrevista, M6 conversava com B6 de maneira carinhosa e a elogiava, além de demonstrar satisfação com a experiência de maternidade.

\section{Discussão}

Dentre os seis casos descritos nesse estudo, as três primeiras mães (M1, M2 e M3) representaram a vivência da maternidade com a presença de depressão pós-parto. Já os três casos restantes (M4, M5 e M6) descreveram a maternidade de mães sem depressão pós-parto. A partir da análise dos dados, foi possivel identificar a existência de percepções negativas a respeito da experiência de gestação, que possivelmente é influenciada pela presença da depressão pós-parto, assim como sugere a literatura (Sousa et al., 2011).

Infere-se, com base nos resultados apresentados, que as mães com depressão pósparto entrevistadas trouxeram, em seus relatos, aspectos que sugerem a presença de sintomas de humor deprimido durante suas gestações. É relevante destacar que no caso de uma das mães com depressão pós-parto (M3), a médica que realizava o acompanhamento pré-natal identificou a presença de sintomas depressivos durante o processo gestacional, apesar de não ter realizado encaminhamentos. Sobre esse tema, a literatura aponta que mães com sintomas próprios da depressão durante a gravidez costumam ter percepções negativas sobre sua experiência de gestação e de maternidade (Eastwood et al., 2012; Lancaster et al., 2010). Ainda, de acordo com Lancaster et al. (2010) uma mulher deprimida durante a gestação pode lembrar da concepção como involuntária. Isso aparece nesta investigação através dos relatos das mães com depressão pósparto de não planejamento das gestações e de dificuldades frente à aceitação dessas.

Nos casos de mães com depressão pósparto, apenas uma mãe relatou ter planejado sua gestação (M2). Porém, ao mesmo tempo, essa mãe deixou dúbio o seu desejo, visto que, quando questionada, descreveu a vontade de ter um filho que seu companheiro sentia na época 
e não o seu próprio desejo. Durante a entrevista, M2 problematizou o momento em que a gestação aconteceu em sua vida, deixando pouco claro seu desejo pela gestação. Ainda nas situações de depressão pós-parto, dois casos destacaramse por seus relatos de gestações não desejadas e não planejadas (M1 e M3). Dentre as mães sem depressão pós-parto, todas desejaram e planejaram suas gestações. Esses achados corroboram com a literatura, a qual aponta que o não desejo de uma gestação é fator de risco para a depressão das mães (Abassi et al., 2013).

Para além da investigação proposta, destacase que o desejo e o planejamento podem ser investigados, ainda, pela perspectiva do pai e de seu apoio durante a gestação, que diz muito da relação entre mãe-pai-bebê. Imaginar as caracteristicas psicológicas e fisicas do bebê, são formas de os pais se incluírem na vivência da gestação, além de estreitar a relação entre pai e bebê (Piccinini, Levandowski, Gomes, Lindermeyer, \& Lopes, 2009). Nos casos estudados de depressão pós-parto, de acordo apenas com o relato materno, somente um pai (P2) desejava a gestação. No entanto, o envolvimento do pai no processo gestacional foi pouco descrito, situação que se repetiu nos outros dois casos de mães com depressão pós-parto (M1 e M3). Já nos casos de mães sem depressão pós-parto (M4, M5 e M6), essas fizeram elogios aos companheiros e à participação deles durante a gestação.

Ainda, a literatura aponta para a importância das verbalizações de sentimentos e de expectativas e o quanto essas falas são fundamentais para a construção de uma representação mental sobre o bebê durante a gestação (Piccinini, Gomes, Moreira, \& Lopes, 2004). No presente estudo, observouse que as expectativas quanto às experiências de contato com o bebê - ou a ausência delas também dizem respeito ao processo gestacional. Enquanto mães não deprimidas (M4, M5 e M6) mostraram, especialmente, expectativas positivas frente à chegada do bebê, as mães deprimidas (M1, M2 e M3) destacaram-se por relatos negativos frente às experiências de contato com o bebê. Como exemplo, evidencia-se o relato de M1 (M1, comunicação pessoal, 23 Fev. 2014), que contou que os momentos que costumavam gerar emoção e expectativa nas grávidas, como a ultrassonografia, ela "fazia sem afeto, fazia sem emoção".

A ansiedade e o estresse materno, assim como o fato de a gestação ser indesejada, destacamse na literatura por sua possivel relação com os sintomas da depressão pré-natal (Abassi et al., 2013: Cantilino et al., 2010; Lancaster et al., 2010; Robertson et al., 2004). Observou-se, no presente estudo, que a necessidade de transformação que acompanha o processo de gestação parece ter sido um fator ansiogênico para as mães deprimidas que foram investigadas.

Por fim, sobre a relação entre a depressão e a maternidade, foi possivel identificar os diversos sentimentos das participantes a respeito de suas experiências de gestação. Enfatizam-se os relatos de irritabilidade, perda de interesse pelas atividades habituais e pela organização do enxoval do bebê, sentimento de culpa e dificuldade na aceitação da notícia da gestação presentes nas falas das entrevistadas com depressão pós-parto. Como contraponto, as mães não deprimidas expuseram, também, algumas preocupações e ansiedades frente à maternidade, porém demonstraram maior capacidade de enfrentamento. Através dos relatos, evidenciou-se que as mães deprimidas possuiam percepções negativas acerca de suas experiências de gestação, cada qual com sua particularidade, especialmente relacionada à situação de vida na qual essa ocorreu (Sousa et al., 2011).

\section{Considerações finais}

Como apontado por Campos e Rodrigues (2015), a depressão materna, mesmo em sua forma mais branda, pode afetar a relação mãebebê. Comumente, as mães podem apresentar, em diferentes graus, sintomas de depressão diante da responsabilidade de cuidar de seu bebê e de lidar com as demandas de adaptação frente à nova etapa de vida.

Diante das evidências do estudo realizado, acredita-se que os sintomas de depressão materna podem anteceder o puerpério, possivelmente manifestando-se já na gestação. 
A dificuldade em aceitar o processo gestacional e suas implicações, especialmente no caso de gestações não planejadas e indesejadas, sugere que a mãe pode estar vivenciando uma experiência de maternidade conflituosa, a qual pode estar associada a sintomas depressivos. A necessidade de reorganização psíquica que a gestação exige da mulher pode, muitas vezes, ser um processo de grande sofrimento.

Esse estudo corroborou, ainda, com os achados da literatura que indicam que mães com depressão pós-parto tendem a ter uma percepção negativa da sua experiência de gestação e maternidade (Eastwood et al., 2012; Lancaster et al., 2010). A percepção que a mulher tem sobre si mesma como mãe - é muito importante e diz respeito à sua autoestima. Vivenciar sensações de desilusão, fracasso e decepção frente à maternidade, além da preocupação de estar interferindo, de alguma forma, no desenvolvimento de seu filho, são situações muito dificeis enfrentadas por todas as mães em algum momento, especialmente pelas mães deprimidas (Maldonado, 2002). Reconhecer e admitir a existência de aspectos negativos nas vivências da maternidade nem sempre é uma tarefa fácil para as mães.

As limitações desse estudo incluem a análise de um pequeno número de casos, bem como o fato de não ser longitudinal e de possuir uma abordagem retrospectiva da experiência de gestação com mães deprimidas, ou seja, sujeita ao viés de memória. Portanto, sugere-se a realização de novos estudos sobre a temática, especialmente longitudinais, que possam confirmar os dados encontrados, bem como contribuir para maiores achados a respeito da experiência de gestação em mães com depressão pós-parto.

Frente à literatura estudada e aos dados encontrados nesta análise, sugere-se que o trabalho de prevenção e tratamento da depressão materna seja prioridade não somente na situação pós-parto, mas também na etapa pré-natal. As equipes de saúde que fornecem apoio às grávidas precisam estar atentas às evidências de que as mães possam estar enfrentando de forma atípica os desafios da experiência de maternidade. Abrir espaço para dialogar sobre os sofrimentos dos processos da gestação e do pós-parto é fundamental para que a mulher possa discorrer sobre seu cansaço, seus medos, sua falta de paciência e, até mesmo, sobre seu desespero diante das novas responsabilidades trazidas pela maternidade.

Muitas mães deprimidas costumam buscar auxilio somente quando o bebê já tem cerca de nove meses de vida, apesar de referirem a presença de sintomas de depressão anteriores a esse periodo (Nonacs \& Coehn, 2005). Os sintomas, muitas vezes, são negligenciados pela própria mulher, que relaciona seu humor deprimido ao excesso de atividades do período após o parto. $O$ atendimento precoce à mãe deprimida representa a prevenção do estabelecimento de uma interação negativa com o bebê - responsável por repercussões em seu desenvolvimento (Milgrom \& Gemmill, 2014) - e, portanto, a atenção à saúde mental tanto da mãe quanto de seu bebê. Assim como em outras investigações (Arrais et al., 2014; Eastwood et al., 2012; Howard et al., 2014: Sousa et al., 2011), entende-se que a ciência psicológica deve se dedicar, cada vez mais, aos trabalhos que visam à prevenção e ao tratamento da depressão pré e pós-parto.

\section{Referências}

Abassi, S., Chuang, C. H., Dagher, R., Zhu, J., \& Kjerulff., K. (2013). Unintended Pregnancy and Postpartum Depression Among First-Time Mothers. Journal of Women's Health, 22(5), 412-416. 10.1089/jwh.2012.3926

Aliane, P. P., Mamede, M. V., \& Furtado, E. F. (2011). Revisão Sistemática sobre Fatores de Risco Associados à Depressão Pós-parto. Psicologia em Pesquisa, 5(2), 146155. Retrieved from http://pepsic.bvsalud.org/scielo. php? script=sci_arttext\&pid=S1982-12472011000200007 (DOI INEXISTENTE)

Alvarenga, P., \& Frizzo, G. B. (2017). Stressful Life Events and Women's Mental Health During Pregnancy and Postpartum Period. Paidéia, 27(66), 51-59. 10.1590/198243272766201707

American Psychological Association. (1994). Manual diagnóstico e estatístico de transtornos mentais (4a ed.). Porto Alegre, RS: Artmed.

American Psychological Association. (2013). Manual diagnóstico e estatistico de transtornos mentais (5a ed.; M. I. C. Nascimento et al., Trads.). Porto Alegre, RS: Artmed. 
Amorin, P. (2000). Mini International Neuropsychiatric Interview (MINI): validação de entrevista breve para diagnóstico de transtornos mentais. Revista Brasileira de Psiquiatria, 22(3), 106-115. 10.1590/S151644462000000300003

Arrais, A. R., Mourão M. A., \& Fragalle, B. (2014). O pré-natal psicológico como programa de prevenção à depressão pós-parto. Saúde e Sociedade, 23(1), 251264. 10.1590/S010412902014000100020

Brockington, I., Butterworth, R., \& Glangeaud-Freudenthal, N. (2016). An international position paper on mother-infant (perinatal) mental health, with guidelines for clinical practice. Archives on Women's Mental Health, 20, 113-120. doi: 10.1007/s00737-016-0684-7

Camacho, R. S., Cantinelli, F. S., Ribeiro, C. S., Cantilino, A., Gonsales, B. K., Braguittoni, Ė., \& Rennó Jr, J. (2006). Transtornos psiquiátricos na gestação e no puerpério: classificação, diagnóstico e tratamento. Revista de Psiquiatria Clínica, 33(2), 92-102. doi: 10.1590/S010160832006000200009

Campos, B. C. D., \& Rodrigues, O. M. P. R. (2015). Depressão pós-parto materna: crenças, práticas de cuidado e estimulação de bebês no primeiro ano de vida. Psico, 46(4), 483-492. 10.15448/1980-8623.2015.4.20802

Cantilino, A., Zambaldi, C. F., Sougey, E. B., \& \& Rennó Jr., J. (2010). Transtornos psiquiátricos no pós-parto. Revista de Psiquiatria Clínica, 37(6), 278-284. 10.1590/ S0101-60832010000600006

Cruz, E. B. S., Simões, G. L., \& Faisal-Cury, A. (2005). Rastreamento da depressão pós-parto em mulheres atendidas pelo Programa de Saúde da Família. Revista Brasileira de Ginecologia e Obstetricia, 7(4), 181-188. 10.1590/S0100-72032005000400004

Eastwood, J. G., Jalaludin, B. B., Kemp, L. A., Phung, H. N., \& Barnett, B. E.W. (2012). Relationship of postnatal depressive symptoms to infant temperament, maternal expectations, social support and other potential risk factors: findings from a large Australian cross-sectional study. BioMed Central Pregnancy and Childbirth 12(148), 1-11. 10.1186/1471-2393-12-148

Field, T. (2017). Prenatal depression risk factors, developmental effects and interventions: a review. Journal of pregnancy and child health, 4(1), 1-25. doi: 10.4172/2376$127 X .1000301$

Frizzo, G. B., Piccinini, C. A., Silva, M. R., Levandowski, D. C., Donelli, T. S. (2012). Depressão pós-parto: prevalência, antecedentes e intervenção. Projeto de pesquisa não publicado. Instituto de Psicologia, Universidade Federal do Rio Grande do Sul. Porto Alegre, Brasil.

Frizzo, G. B., Prado, L. C, Linares, J. L, \& Piccinini, C. A. (2010). Depressão pós-parto: evidências a partir de dois casos clínicos. Psicologia Reflexão \& Crítica, 23(1), 46-55. doi: 10.1590/S0102-79722010000100007

Gazal, M., Motta, L. S., Wiener, C. D., Fernandes, J. C., Quevedo, L. A.., Jansen, K., \& Oses, J. P. (2012). Brain-derived neurotrophic factor in post-partum depressive mothers. Neurochemical research, 37(3), 583-587. 10.1007/s11064-011-0647-3
Haran, C., Van Driel, M., Mitchell, B. L., \& Brodribb, W. E. (2014). Clinical guidelines for postpartum women and infants in primary care-a systematic review. BioMed Central Pregnancy and Childbirth, 14(1), 51. 10.1186/1471-2393-14-51

Henriques, C. M. G., Santos, M. L. F. C. D., Caceiro, E. M. D. S. F., \& Ramalho, S. I. H. S. M. (2015). Determinantes na transição para a parentalidade. Revista Portuguesa de Enfermagem de Saúde Mental, 2, 63-68. Retrieved from http://Www.scielo.mec.pt/pdf/rpesm/nspe2/ nspeza11.pdf (DOI INEXISTENTE)

Howard, L. M., Molyneaux, E., Dennis, C. L., Rochat, T., Stein, A., \& Milgrom, J. (2014). Non-psychotic mental disorders in the perinatal period. Lancet, 384, 1775-1788. doi: 10.1016/S0140-6736(14)61276-9

Lancaster, C. A., Gold, K. J., Flynn, H. A., Yoo, H., Marcus, S. M., \& Davis, M. M. (2010). Risk factors for depressive symptoms during pregnancy: a systematic review. American Journal of Obstetrics \& Gynecology, 202(1), 5-14. 10.1016/j.ajog.2009.09.007

Maldonado, M. T. (2002). Psicologia da Gravidez: Parto e Puerpério (16a ed.). São Paulo, SP: Saraiva.

Megnin-Viggars, O., Symington, I., Howard, L. M., \& Pilling, S. (2015). Experience of care for mental health problems in the antenatal or postnatal period for women in the UK: a systematic review and meta-synthesis of qualitative research. Archives of women's mental health, 18(6), 745-759. 10.1007/s00737-015-0548-6

Milgrom, J., \& Gemmill, A. W. (2014). Screening for perinatal depression. Best Practice \& Research Clinical Obstetrics \& Gynaecology, 28(1), 13-23. 10.1016/j.bpobgyn.2013.08.014

Moraes, I. G. M, Pinheiro, R. T., Silva, R. A., Horta, B. L., Souza, P. L. S., \& Faria, A. D. (2006). Prevalência da depressão pós-parto e fatores associados. Revista de Saúde Pública, 40(1), 65-70. doi: 10.1590/So03489102006000100011

Nonacs, R., \& Cohen, L. S. (2005). Postpartum psychiatric syndromes. In B. J. Sadock \& Sadock (Eds.), Kaplan \& Sadock's comprehensive textbook of psychiatry (8th ed.) (pp. 1276-1283). Philadelphia, PA: Lippincott Williams \& Wilkins.

Nudif. (2003). Entrevista sobre Gestação e Parto. Instituto de Psicologia, UFRGS, Porto Alegre. Instrumento não publicado.

Piccinini, C. A., Carvalho, F. T., Ourique, L. R., \& Lopes, R. C. S. (2012). Percepções e sentimentos de gestantes sobre o pré-natal. Psicologia: Teoria e Pesquisa, 28(1), 27-33. doi: 10.1590/S0102-37722012000100004

Piccinini, C. A., Levandowski, D. C., Gomes, A. G., Lindermeyer, D., \& Lopes, R. C. S. (2009). Expectativas e sentimentos de pais em relação ao bebê durante a gestação. Estudos de Psicologia, 26(3), 373-382. 10.1590/ So $103-166 \times 2009000300010$

Piccinini, C. A., Gomes, A. G., Moreira, L. E., \& Lopes, R. C. S. (2004). Expectativas e sentimentos da gestante em relação a seu bebê. Psicologia: Teoria e Pesquisa, 20(3), 223-232. doi: 10.1590/S0102-37722004000300003 
Robertson, E., Grace, S., Wallington, T., \& Stewart, D. E. (2004). Antenatal risk factors for postpartum depression: a synthesis of recent literature. General hospital psychiatry, 26(4), 289-295. doi: 10.1016/j.genhosppsych.2004.02.006

Santos, I. S., Matijasevich, A., Tavares, B. F., Barros, A. J., Botelho, I. P., \& Lapolli, C. (2007). Validation of the Edinburgh Postnatal Depression Scale (EPDS) in a sample of mothers from the 2004 Pelotas Birth Cohort Study. Cadernos de Saúde Pública, 23(11), 2577-2588. 10.1590/S0102-311X2007001100005

Sheehan, D. V., Lecrubier, Y., Sheehan, K. H., Amorim, P., Janavs, J., Weiller, E., ... \& Dunbar, G. C. (1998). The Mini Internacional Neuropsychiatric Interview (MINI): the development and validation of a structured diagnostic psychiatric interview for DSM-IV and CID- 10. Journal of Clinical Psychiatric, 59(20), 22-33. 10.1590/ S1516-44462000000300003

Sousa, D. D., Prado, L. C., \& Piccinini, C. A. (2011). Representações acerca da maternidade no contexto da depressão pós-parto. Psicologia Reflexão e Crítica, 24(2), 335-343. 10.1590/S0102-79722011000200015

Wisner, K. L., Sit, D. K., McShea, M. C., Rizzo, D. M., Zoretich, R. A., Hughes, C. L., ... \& Hanusa, B. H. (2013). Onset timing, thoughts of self-harm, and diagnoses in postpartum women with screen-positive depression findings. JAMA psychiatry, 70(5), 490-498. 10.1001/ jamapsychiatry.2013.87

Yin, R. K. (2015). Estudo de caso: planejamento e métodos (5a ed.; C. M. Herrera, Trads.). Porto Alegre, RS: Bookman.

\section{Monique Souza Schwochow}

Doutoranda e Mestra em Psicologia pela Universidade Federal do Rio Grande do Sul (UFRGS), Porto Alegre, RS, Brasil.

\section{Giana Bitencourt Frizzo}

Doutora em Psicologia pela Universidade Federal do Rio Grande do Sul (UFRGS, Porto Alegre, RS, Brasil). Professora da Universidade Federal do Rio Grande do Sul em Porto Alegre, RS, Brasil.

\section{Endereço para correspondência}

\section{Monique Souza Schwochow}

Universidade Federal do Rio Grande do Sul - Instituto de Psicologia

Rua Ramiro Barcelos, 2600, sala 212.

Santa Cecilia, 90035003

Porto Alegre, RS, Brasil 